\title{
Identification and processing of a frame structure
}

\author{
Shang Xiang ${ }^{1, a}$,Xuerui Yang ${ }^{1, b}$,Guobo Luo, c \\ ${ }^{1}$ Guizhou Construction Science Research \& Desigh Institute Co. Ltd, Guiyang 550000, China \\ a337198249@qq.com, bxuerui.yang@126.com, c745630455@qq.com
}

Keywords: engineering quality, inspection, strengthening

Abstract. In recent years, the construction engineering industry has developed rapidly, and the engineering quality problems have become increasingly prominent, such as the low concrete strength and the cold joints of concrete structures. Based on an engineering example, this paper describes the whole process of the detection and identification of a frame structure and the reinforcement process, which provides reference for similar project detection and identification and reinforcement treatment.

\section{Project overview}

A building structure form for five layer frame structure, the basic form of pile foundation, floor, roof boarding for site casting, the roof for roofing and seismic fortification intensity is less than 6 degrees, use fixed number of year for 50 years, the main structure of the design level of building structure security for level ii.

\section{Determine the cause and purpose}

Due to the cracking phenomenon of the building beam, the entrusting party commissioned my unit to inspect and identify the building, and took corresponding measures to strengthen the construction of the building.

\section{Test content}

According to the preliminary view, and on the basis of ${ }^{[1]}$ to the purpose and the relevant specification, my unit of problems for the project of the building construction quality inspection, test content is as follows: developed concrete member section size detection, to detect the thickness of the protective layer of concrete components, reinforced configuration testing, concrete member strength testing, the concrete appearance quality and defect detection.

\section{Test results}

On site inspection, the section size of the components, the thickness of the protective layer of concrete members and the configuration of the steel reinforcement are all satisfied with the design and acceptance specifications ${ }^{[2]}$. The concrete strength of some components does not meet the design requirements, and the concrete beams have defects in appearance.

Strength test results of beams and columns. For site inspection found that part of the strength of concrete member does not meet the design requirements, design strength for the $\mathrm{C} 30$, for saving the cost of reinforcement, so the strength of all concrete beam and column components to test, test results are shown in table 1 and table 2, the test results shows that column concrete strength above C20, part of the beam concrete strength is lower than C20。 
Table 1 column concrete strength test result table

\begin{tabular}{|c|c|c|c|}
\hline artifacts & {$[\mathbf{C 2 0} \sim \mathbf{C 2 5})$} & [C25 C30) & greater thanC30 \\
\hline first floor & $37.29 \%$ & $25.42 \%$ & $37.29 \%$ \\
\hline second floor & $33.33 \%$ & $41.27 \%$ & $25.40 \%$ \\
\hline third floor & $41.94 \%$ & $14.52 \%$ & $43.55 \%$ \\
\hline fourth floor & $31.37 \%$ & $47.06 \%$ & $21.57 \%$ \\
\hline fifth floor & $44.07 \%$ & $44.07 \%$ & $11.86 \%$ \\
\hline
\end{tabular}

Table 2 test results of beam concrete strength

\begin{tabular}{|c|c|c|c|c|}
\hline artifacts & {$[\mathbf{C 1 5} \sim \mathbf{C 2 0})$} & {$[\mathbf{C 2 0} \sim \mathbf{C 2 5})$} & {$[\mathbf{C 2 5} \sim \mathbf{C 3 0})$} & Greater \\
\hline second floor & $6.83 \%$ & $44.72 \%$ & $16.77 \%$ & $31.68 \%$ \\
\hline third floor & $2.01 \%$ & $52.35 \%$ & $36.91 \%$ & $8.72 \%$ \\
\hline fourth floor & $3.14 \%$ & $42.77 \%$ & $14.47 \%$ & $39.62 \%$ \\
\hline fifth floor & $2.35 \%$ & $42.94 \%$ & $32.94 \%$ & $21.76 \%$ \\
\hline roof floor & $1.32 \%$ & $52.98 \%$ & $29.80 \%$ & $15.89 \%$ \\
\hline
\end{tabular}

Component defects.On site detection, the beam defects are mainly divided into two types: 1) the beam is inclined to the construction crack, and this kind of crack is the penetrating crack; 2) the beam end of the frame is inclined to crack, and the crack is the penetrating crack.

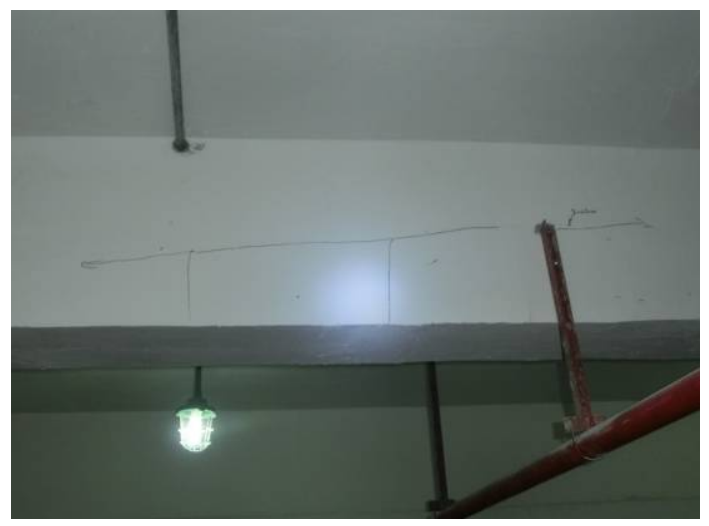

Fig.1The beam is inclined towards the construction crack

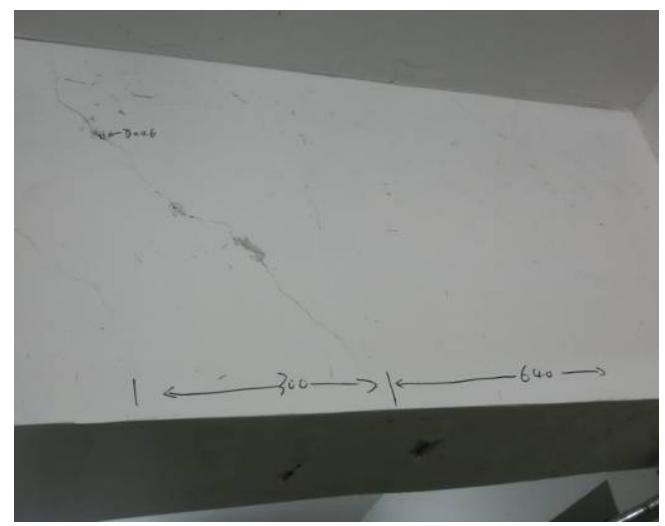

Fig. 2 Frame beam end inclined to crack.

Bearing capacity checking.According to the actual testing situation, according to the current standard ${ }^{[3],[4]}$ the bearing capacity of the structure is checked, and the bearing capacity of some beams and columns does not meet the requirements.

\section{Reinforcement design}

Reinforcement design thinking .According to the result of checking calculation, the beam and column of all bearing capacity are not satisfied. The beam is inclined toward the construction crack 
and the beam end inclined toward the crack, can affect the bearing capacity of the beam, so to exist above two kinds of cracks in the beam to reinforce the treatment.

Reinforcement design method.For the column with insufficient bearing capacity, it is used to strengthen the cross section ${ }^{[5]}$ method, and the beam with insufficient bearing capacity is treated with a larger section method. For the beams with the bearing capacity and the cracks, the beam is treated by the external viscosified steel method after the pressure grouting of the beam cracks. The schematic diagram is as follows.

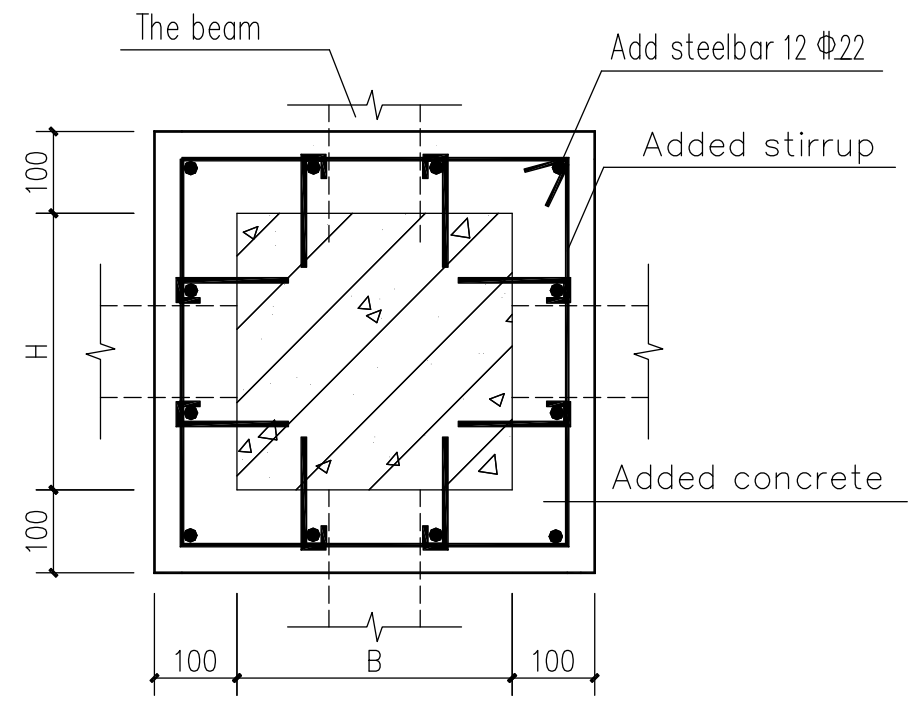

Fig. 3 Stiffening column of cross section method

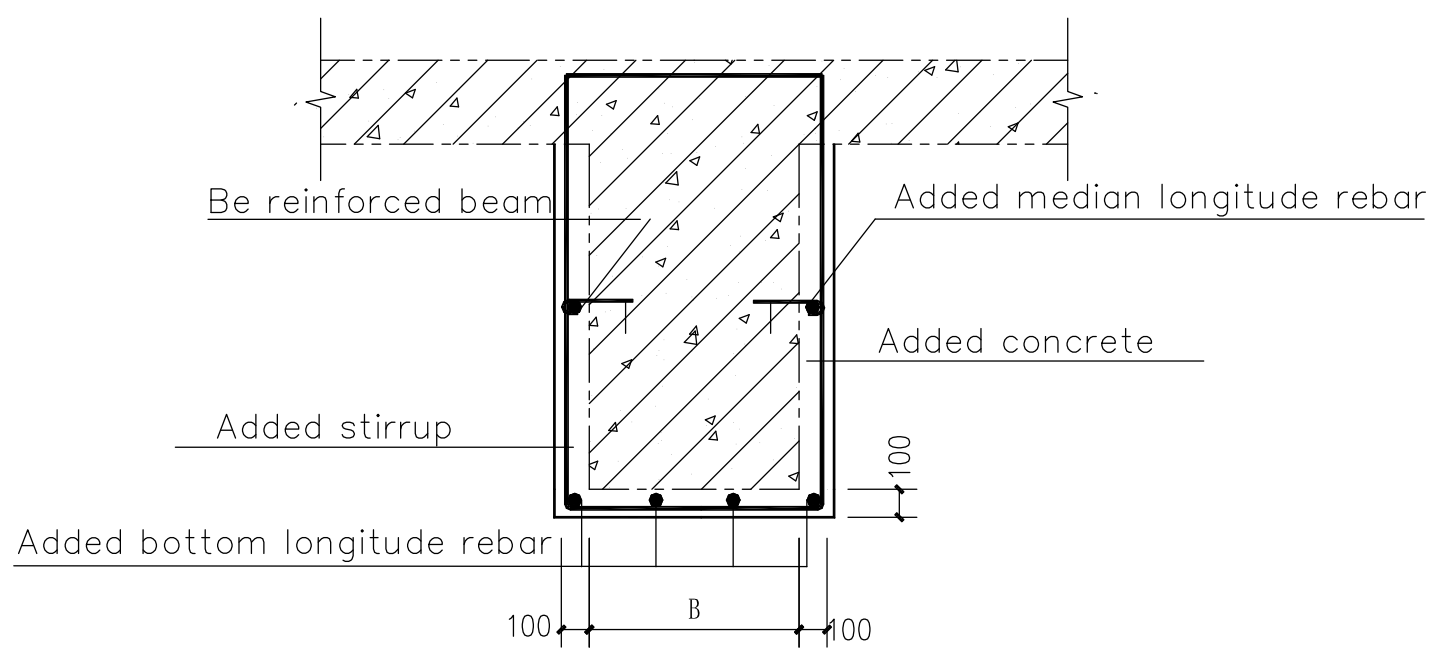

Fig. 4 Stiffening beam of section method 


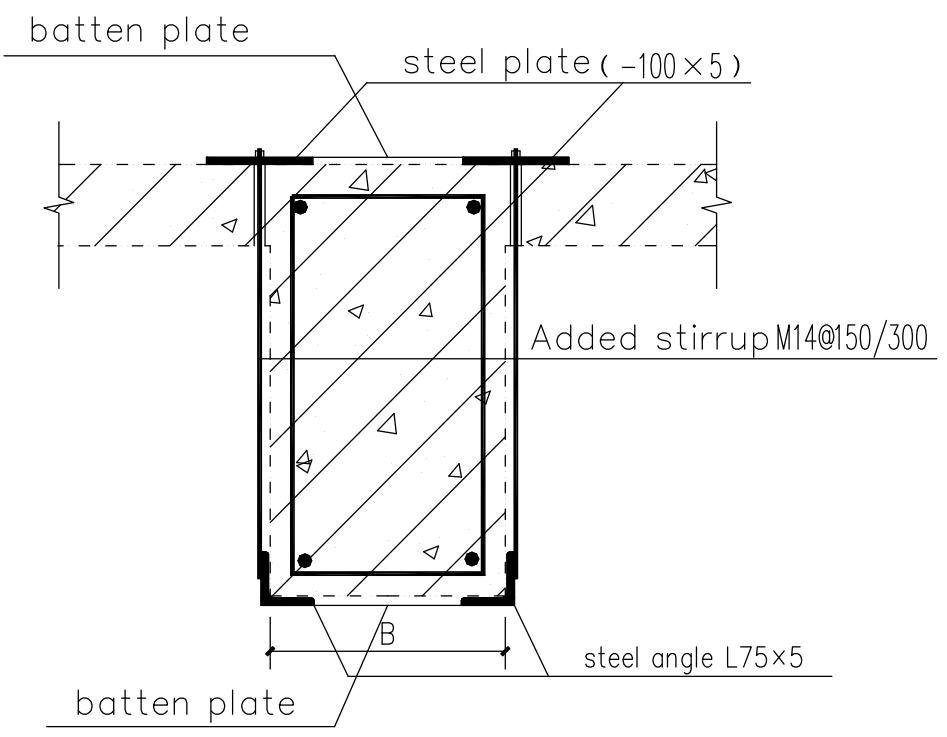

Fig. 5 Reinforced beam with external bonding steel

\section{Conclusion}

1) After the above treatment, the building is in good condition;

2) The engineering quality problem should be given high attention, and the process management should be strengthened to minimize the appearance of quality problems;

3 ) For the quality problem, the quality problem should be treated with scientific method and reinforcement method to achieve the desired effect.

\section{References}

[1] 《Technical standard for inspection of building structure》(GB/T 50344-2004);

[2] 《Code for acceptance of construction quality of concrete structures(GB50204-2015);

[3] 《Code for design of concrete structures》(GB50010-2010);

[4] 《Load code for the design of building structures》(GB 50009-2012);

[5] 《Design code for strengthening concrete structures》(GB50367-2013) . 